\title{
Management and Adaptive Control of the Manufacturing System
}

\author{
DASCHIEVICI LUIZA, GHELASE DANIELA \\ Faculty of Engineering \\ "Dunarea de Jos" University of Galati \\ Calea Calarasilor, nr. 29, 810017, Braila \\ ROMANIA \\ luiza.tomulescu@ugal.ro
}

\begin{abstract}
Competitiveness fully and sy nthetically characterizes the viabil ity of an enterprise. In $t$ he economics literature competitiveness is analyzed in particular in economic and managerial terms with almost no insight into the analysis of the technology role in ensuring and developing competitiveness.

Hence the need for manufacturing s ystems based on behavioral modeling and on line learning. The behavioral approach is based on a continuous awaren ess of the situations a nd decisions in real tim e on activities. Thus it can provide solutions to make manufacturing systems develop and be competitive. From theories of knowledge and com plexity, we can design a flexible system that will lead to manufacturing processes, flexibly responding to any environmental demand. The behavioral management is characterized by the ability to perceive the environment, to take decision in time, as a result of interaction, with no specific procedures. The sy stem environment provides on -line data on the actions undertaken which, prop erly analyzed and correlated, will further generate solu tions in order to develop said s ystem and make it competitive. The paper aim $\mathrm{s}$, in the field of ma nufacturing technologies, at approaching issues of manufacturing systems, in order to develop a new concept of management, which is in line with the current market dynamics: the concept of competitive management.

The concept of com petitive management can offer solutions even to $\mathrm{m}$ ake com petitive and devel op enterprises as a whole.
\end{abstract}

Key-Words: - competitive management, manufacturing system, competitiveness, on-line learning, adapt ive control, technical-economical characteristics of manufacturing system

Received: November 8, 2019. Revised: March 1, 2020. Accepted: March 24, 2020. Published: April 18, 2020.

\section{Introduction}

On worldwide plan, entreprises ar e confronted with a dynamics more and more an accelerated the si impredictible changes. T his is influenced by the technical and scientifical progres s, dynamic requirements of the customers, science of management and $\mathrm{m}$ athematical e econom $\mathrm{y}$. These changes enforce an aggre ssive competition to the global scale what assu me the requirest of a ne w settlement echilibre between econom y, technology and society. To this challange, the scientific community proposes to answer ne $\mathrm{w}$ paradigm: Knowledge-based Economy. From theories of knowledge and complexity, we can design a flexible system that will lead to manufacturing processes, flexibly responding to an y environmental demand. The behavioral management is characterized by the ability to perceive the environm ent, to take decision in time, as a result of int eraction, with no specifi c procedures.
The characteristic aspects of the present-day market, in particular case of mechanical components market, are the following: i) cont inuously decreasing of the current orders, leading to the design of sm all series production; ii) strong ten dency to personalize the products leads to a pronou nced diversity of shapes, sizes and other character istics of the mechanic al components required on the market; iii) flexibility, responsiveness and especially an effi cient system management tend to become the characteristics that determine competitiveness on the market of components manufacturers and mechanical constructions. The current dynamics of the industrial and business environme nt is the great global challenge which must be faced.

In literature, an enterprise is a competitive on a certain the market when it obtains certain econom ic indicator: encipher of business, profits, seg ments of the comparable his superior $m$ arket with one have another competitors.

Thence, it follows at the current level the 
competitiveness is defined by the economical factors and indicators obtained and is it more a suggested notion than a numerical evaluated. Don't exist, in this moment, defined an algorithm for the evaluation technical-economical competitiveness, because th e factors of technical nature don't take in consideration for the definiteness of com petitiveness, although the consumptions and the ne cessary expenditures of technological process are new generated by technical actions. This in contex, the competitiveness notion gets new valences, it gathering factors and which politics determ ine just the capacity of the enterprises dealt a favorable place on the market, kept that place and of i mprove continuously the position. The com petitiveness characterizes synthetically and complete viability of the enterprises.

The most important feature of the present-day market is the high level of customizing the products requested by customers, which brings about a large variety of the requested products and a small volume of the batches in which these $p$ roducts are manufactured.

One of the $r$ esponses which can be gi ven to this challenge is to increase its responsiveness by continuously reconfiguring the manufacturing systems in com pliance with the task to be carried out. In order to make this happen, manufacturing systems are either fo $r$ general purpose or reconfigurable.

According to the liter ature, a com pany is competitive on a certain market when it succeeds to reach, up to an ac ceptable level, so me economic indicators: turnover, profit, market share comparable or superior to that of other co mpeting companies acting on the same market.

Many approaches to the problem of competitiveness [2] show that, today, competitiveness is defined by the economic factors and indicators obtained and is more a suggested notion than a num erically evaluated one.

The indicator of performance proposed in this paper, for the modeling of these sy stems, is to be both holistic (in the sense that it takes into account not only the econom ic but also the technical performance) and s ynthetic (in the sense that it reflects key aspects of the manufact uring system functionality, namely those that are closely related to the reason for which they were created).

In the paper the co mpetitiveness is considered an indicator, both holistic and sy nthetic, of the technical-economic performance and is used as a criterion for the modeling of manufacturing systems. This paper refers to the manufacturing system management/control, so as to $\mathrm{m}$ aximize their technical and econom ic performance. So in other words, to maximize the economic performance of manufacturing system through adequate selection of task assigned.

In the paper it is proposed an algorithm for th e economic \& technical rules identification and $i t$ is presented its application for a drilling process.

The KDD (Knowledge Discovery from Databases) is applied for determ ines the rules of the drilling process that are further used in the technicaleconomic model as inpu t data. KDD consists in identification of the clusters of the process parameters that are connected to the other clusters of the market environment.

The aim of modeling is to maxim ize the econom ic performance of a manufacturing system by selecting a suitable task assigned.

\section{Problem formulation}

The manufacturing system performance depends on how it is manage. In $\mathrm{m}$ ore specialized papers, reference is made to the relationships between the process parameters and the technical performance of the manufacturing system (purely technical aspects), while in others, refer ences are made to th $e$ relationship between the product $m$ ade by the manufacturing system and the market (economic relations).

In the literature no attempt to approa ch the whole manufacturing system - market assembly is reported; therefore, there are significant resources to improve performance whi ch are not used becaus e the technical and econom ic aspects are dealt with separately.

Also, it is not kn own an algorithm for th e management of the $m$ anufacturing system - market assembly, but only algorithms for the technical control of the technological sy stems-components of the manufacturing s ystem and tools of economic management of the $r$ elationship between the enterprise as a whole and the market [1], [3].

The interaction between the econom ic environment and the man ufacturing system is a major source of knowledge about the economic environment and the manufacturing system themselves.

The manager of an enterprise is in the situation that has to $m$ ake a quotatio $n$ of price for elaborate an offer in order to negotiate.

Thus, the question that occurs is: how com petitive is the product on the market?

To answer at this question, the manager is obliged to establish a link between task and performance or profit of manufacturing system in order to negotiate the contract. The link between task an d performance 
is built on a $\mathrm{m}$ athematical relationship, using datasets, created by the manufacturing system, in situations similar but not identical. In other words, knowing this relationship, the $\mathrm{m}$ anager will $\mathrm{m}$ ake control based on com petitiveness (performance) of manufacturing system and will negotiate the contract in effective terms.

Adaptive control of the manufacturing system occurs when must be obtained a batch of parts in certain circumstances: time, cost, etc. In this case, the mathematical model have to be modified, so to respect the requirements and will be modify process parameters. Well, another set of data known, is a new mathematical model (another relationship taskperformance) with other process parameters in order to see how to change the behaviour of

manufacturing system.

The problem is the following: giving a batch of parts to be manufactured, in term $\mathrm{s}$ of working time required and a minimum cost, to evaluate th $\mathrm{e}$ process parameters to assure com pliance (achievement) of these conditions.

\section{Manufacturing competitiveness}

system

In order to survive in the present-day complex and unpredictable environment, the co mpany must feature abilities of quick response and favourably reposition itself on the market. Acquisition an $d$ preservation of this capacity is the most difficult step for companies as it involves many endogenous and exogenous factors and the process is continuous, dynamic and hardly predictable. In this context, three elements are highlighted by their relevance: competitiveness, the manufacturing system and the knowledge system.

According to the literature, a com pany is competitive on a certain market when it succeeds to reach, up to an ac ceptable level, so me economic indicators: turnover, profit, market share comparable or superior to that of other co mpeting companies acting on the same market. Many approaches to the problem of competitiveness [4], [5], [6], [7], [8], [9], [10], [11] show that, today, competitiveness is defined by the economic factors an $\mathrm{d}$ indicators obtained and is more a suggested/induced notion than a numerically evaluated one. In the world there are prestigious co mpetitiveness research centres, such as: Center for International Development-USA Harward University, European Institute of Technology with its research center in Cam bridge, Geneva, Oxford and Organizational Competitiveness Research Unit of Sheffield University Halle-UK which deals with com petitiveness at the global, regional down to enterprise/company level.

However, approaches are of econom ic and managerial nature, while the relationship with the technical aspects of com petitiveness is 1 ess noticeable. At this point there is no defined algorithm to evaluate the technical and econom ic competitiveness, moreover, the technical factors ar e not considered at a pract ical level, w hen defining competitiveness, although consum ption and cost $\mathrm{s}$ incurred by the technological processes ar e generated by technical actions. In this context, the notion of competitiveness gains new valences, including factors and policies that deter mine the ability of the enterprise to get a favourable place on the market, to hold that place and to continuously improve its position. Only in this way can competitiveness fully and sy nthetically characterize the enterprise viability.

In the paper, com petitiveness will be understood as the capacity (potential) to provide performance (compared with other similar elements), in a ver $y$ punctual way, within a macroeconomic concrete context and at a certain time. Moreover, according to a meter of co mpetitiveness (considered as an essential performance indicator) it will be assessed the extent $t \mathrm{o}$ which the co mpany achieves th $\mathrm{e}$ purpose for which it has been created. Therefore the paper aims at making a numerical and on-line evaluation of th e technical- economic competitiveness and the management of the manufacturing system is performed to o btain maximum competitiveness.

The manufacturing system performance depends on how it is run. In $\mathrm{m}$ ore specialized papers [12], [13], reference is made to the relationships between the parameters of the processing regimes and the technical performance of the manufacturing system (purely technical aspects), while in others, equally numerous [14], [15], references are made to the relationship between the product $m$ ade by the manufacturing sy stem and the market (economic relations).

In the literature no attempt to approach the whole manufacturing system - market assembly is reported; therefore, there are significant resources to improve performance whi ch are not used becaus e the technical and econom ic aspects are dealt with separately. Also, it is not known an algorithm for the management of the $\mathrm{m}$ anufacturing system market assembly, but onl y algorithms for the technical control of the technological sy stemscomponents of the manufacturing system and tools of economic management of the relationship between the enterprise as a whole and the market [9], [10]. 
Nowadays, the manufacturing systems are controlled by means of numerically programmed machine tools which are part of the sy stem [7], [8]. The control is exclusively technical because there is no economic variable, although this is actually the ultimate goal of any processing process. The dynamic changes and the overall progress of society are reflect ed at company level by many orders in number, small in volume, very diverse, $\mathrm{o}$ btained through frequent auctions with short- term response, which leaves no time for a relevant analy sis of said o rders. As a result, a long-term management is no lon ger possible. A sort of fluctua ting (just like the market) on-line, fastly responsiv e, prompt and rapid, however, ephemeral management is called for [6].

\section{Control algorithm}

Control algorithm is based on a numerical model, generally and temporary. Parameters values o $\mathrm{f}$ casuistic model are deter mined by " $K$ - nearest neighbour" method, $b$ y analyzing a database obtained by experiments.

The manufacturing system behaviour is changing in time for each batch. This change implies modification of both the model parameters and the causal relations between the model variables.

Generally, for an adaptive control s ystem the model structure remains unchang ed but the $p$ arameters of the model are changed in order for a better modelling of the reality.

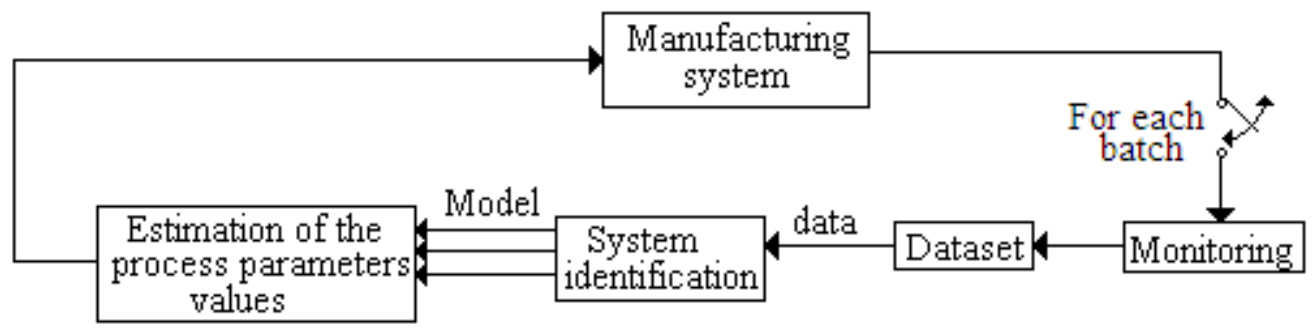

Fig. 1 The proposed control algorithm

The market dynamics is further pas sed to the mode of operation and $\mathrm{m}$ anagement. In a knowledge-based society and econo my, operations such as determ ining the relevant inform ation and aggregating them into pieces of knowl edge must be automated, because in such a complex and unpredictable environment, they are i ndispensable tools for creating, searching and structuring knowledge. The interaction between the econo mic environment and the manufacturing sy stem is a major source of knowled ge about th e economic environment and the manufacturing system themselves [12].
The proposed algorithm consists in the following steps from figure 1.

1. For each processing batch of parts be monitored the parameters of interest (table 1);

2. Monitored data ar e stored and for $m$ dataset for each processed batch of parts;

3. System identification consists in sel ection of all variables groups that could have causal relation and which includes the variable of interest. For each variable group;

4. By means of the obtai ned mathematical models are estimating the process para meters values $t o$ manufacturing system to realize the batch of parts in according to imposed requirements.

Table 1 - Example of experimental data regarding the process variables collected for the drilling process

\begin{tabular}{|c|c|c|c|c|c|c|c|c|c|c|}
\hline $\begin{array}{c}\text { Item } \\
\text { nr. }\end{array}$ & $\begin{array}{c}\text { Type of } \\
\text { material }\end{array}$ & $\begin{array}{c}\text { Hole } \\
\text { diameter } \\
(\mathrm{mm})\end{array}$ & $\begin{array}{c}\text { Number } \\
\text { of } \\
\text { holes }\end{array}$ & $\begin{array}{c}\text { Drilling } \\
\text { speed } \\
(\mathrm{mm} / \mathrm{s})\end{array}$ & $\begin{array}{c}\text { Drilling } \\
\text { feed } \\
(\mathrm{mm} / \mathrm{rot})\end{array}$ & $\begin{array}{c}\text { Number } \\
\text { of } \\
\text { pieces }\end{array}$ & $\begin{array}{c}\text { Machining } \\
\text { time (s) }\end{array}$ & $\begin{array}{c}\text { Energy } \\
\text { consumption } \\
\text { (kwh/ } \\
\text { operation) }\end{array}$ & $\begin{array}{c}\text { Cost of } \\
\text { operation } \\
\text { (Euro/ } \\
\text { operation) }\end{array}$ & $\begin{array}{c}\text { Waste } \\
\text { quantity } \\
(\mathrm{Kg})\end{array}$ \\
\hline- & $\mathrm{V}_{1}$ & $\mathrm{~V}_{2}$ & $\mathrm{~V}_{3}$ & $\mathrm{~V}_{4}$ & $\mathrm{~V}_{5}$ & $\mathrm{~V}_{6}$ & $\mathrm{~V}_{7}$ & $\mathrm{~V}_{8}$ & $\mathrm{~V}_{9}$ & $\mathrm{~V}_{10}$ \\
\hline 1 & OL 52 & 12,5 & 3 & 1,1 & 0,7 & 70 & 7242 & 6,04 & 0,026 & 13,12 \\
\hline 2 & OL 42 & 15,55 & 5 & 4,1 & 0,3 & 28 & 12033 & 3,76 & 0,0268 & 13,54 \\
\hline 3 & OL 42 & 11,6 & 5 & 2,05 & 0,25 & 59 & 6255 & 4,41 & 0,0315 & 15,87 \\
\hline 4 & OL 42 & 25,6 & 2 & 5,05 & 0,35 & 104 & 3404 & 37,86 & 0,108 & 54,52 \\
\hline- & & & & & & & & & & \\
\hline- & & & & & & & & & & \\
\hline- & & & & & & & & & & \\
\hline
\end{tabular}


System identification implies the following steps:

Step 1: clus tering of variables based on the causal relationships;

Step 2: states clustering;

Step 3: buil ding of the mathematical model corresponding to the states cluster and variables cluster set.

Then the causality relationships between param eters are identified. Based on these relationsh ips, clusters of independent variables are establish ed. Further, based on the dataset to be used for the model fitting, a cluster of neighbo uring states is made up, at the centre of which is the state to which the respectiv e input data are related. Finally, a linear m odel whose variables are the variables of one of the clusters o $f$ identified variables is fitt ed on the manufacturing system states cluster. These input data are the ones which have been previousl y considered in th $\mathrm{e}$ procedure of enclosing the manufacturing $\mathrm{s}$ ystem states cluster.

It can be noted that, ac cording to the proposed method, the model construction and its operation are accomplished within an integrated algorithm which is run through upon each interrogation of the manufacturing system model. At the operational level, the variable clustering is based on the "best $N N$ model" facility which is offered by the neural networks technique appl ied to a data set recently obtained from monitoring the manufacturing system. The states cl uster construction, the linear model is fitted to, first $\mathrm{i}$ mplies the use of $\mathrm{t}$ he $2^{\text {nd }}$ rank Minkowski distance for the classification of states, in the increasing order of their distance to the state to be used for model interrogation.

That is why only the variables repre senting these input data will be considered in the calculation of Minkowski distance.

The states cluster is to be obtaine $d$ either by restricting the value of the distance or by restricting the number, $k$, of retained states or using these two conditions.

The construction of the mathematical model is made by linear regression. It ca $\mathrm{n}$ be noted that this is a local model, as it is valid only in the vi cinity of the state for which the model is interrogated. This model is meant to be used $\mathrm{j}$ ust once as, after th $\mathrm{e}$ interrogation, it is given up.

In conclusion, the aim of proposed method is to maximize the econom ic performance of a manufacturing system by selecting a suitable task assigned. This means, to maximize the effect, using the works of the manufacturing system that bring the greatest profit. Criterion which will be used for modelling the co mpetitiveness of manufacturing system is the profit rate, $p$, (rel.1) (performance of the manufacturing system), because the profit rate strongly depends on the product characteristics.

$$
p=(\cos t-\text { price }) / \text { time }
$$

For construction of the task-performance model, which describes the interactio $n$ between manufacturing system and market, we achieved the task-cost manufacturing operation model and the task - market model (fig.2).

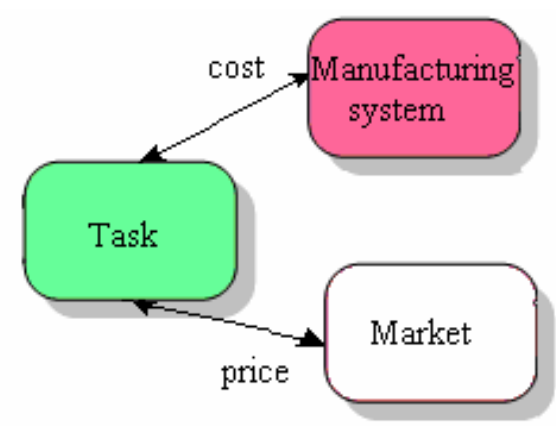

Fig. 2 The interaction between task - manufacturing system and between market - task

The method proposed for achievement of the three models consists in $\mathrm{m}$ onitoring and recording the relevant state variables of the manufacturing system in a database.

\section{Developing the competitive management algorithm to be applied to the manufacturing of mechanical constructions}

By applying the concept developed to the mechanical construction manufacturing systems, the competitive management algorithm for these systems shall be develope $d$. The block schedule on which the com petitive management algorithm is based is illustrated in Figure 3.

The manufacturing system receives contracts after the tenders (competitions) generated by the market offer quotations. The co mpetitive management system means competitiveness assessment, and based on it, an intervention on the m anufacturing system through instructio ns regarding the progress of the manufacturing process in order to obtain maximum competitiveness. On the othe $r$ hand, after assessing competitiveness, the $m$ anagement system should enable to develop com petitive bids for the tenders. To achieve th ese two objectives, the competitive management system makes uses the reinforcement learning to get to know the $\mathrm{m}$ arket and the non supervised on-line learning technique to get to know the manufacturing system.

The behavioural sy stem modelling is to be achieved, based on which the co mpany management 
may intervene in order to elaborate the necess ary instructions to adjust the technological process and elaborate the management policies.

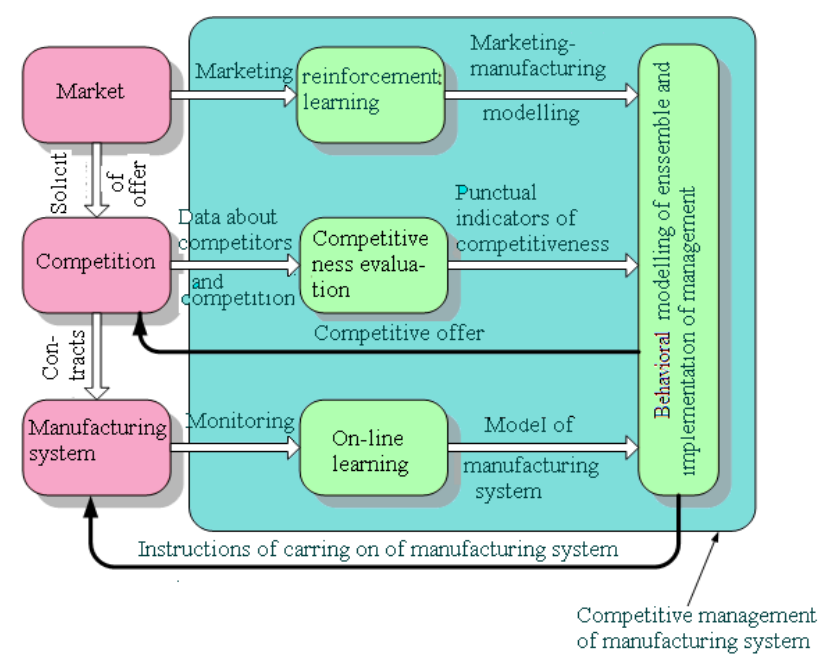

Fig.3. Algorithm of competitive management

Following each line of the co mpetitive management algorithm in Figure 3, the following can be noticed:

i) the algor ithm for modelling the relationship market-manufacturing system implies using the data base from the economic environment (auctions),

extraction of knowledge throug $\mathrm{h}$ data mining and model elaboration $b$ y reinforcement learning techniques;

ii) to obtain the concrete indicators of competitiveness, database from the co mpetitive environment shall be provided and knowledge shall be extracted in order to assess competitiveness;

iii) the market offer quotations enters th $\mathrm{e}$ competitive environment to generate $t$ he contracts for the manufacturing system;

iv) the $\mathrm{m}$ odelling algorithm of the $\mathrm{m}$ anufacturing system is designed starting from the contract specifications and system identification.

Using data mining techniques, data sets on th $\mathrm{e}$ functional and econom ic parameters shall be obtained to be further used to obtain the model of non supervised learning techniques.

Based on the above 1 earning processes the behavioural modelling of the $m$ anufacturing system - market assembly and the $m$ anagement system implementation are achi eved. The manufacturing system receives instructions on the de velopment of the manufacturing processes in order to achieve the maximum level of efficiency (maximum profit).

\section{The advantage of the method compared to the present day methods of manufacturing system management}

1. The method proposed has the advantage of being applicable to any manufacturing system; regardless the physical nature of the process and the prod uct features;

2. Develop a methodology for mathematical assessment of the technical-econom ic competitiveness of the manufacturing system;

3. Develop a new concept of manufacturing systems management based on beha vioral modeling of the market-manufacturing system assembly and on the implementation of the management to the manufacturing system, which is generally applicable and appropriate to the current market demands;

4. Development of behavi oural modelling methods based on no $\mathrm{n}$ supervised on-line learning, which enable adaptive -optim al and predictive control of the manufacturing systems;

5. This type of management provides managers: the possibility of rapid price quotations of its products, a software representing the co mpany model and which generates instructions in the progress of manufacturing processes (Fig. 3), the possibilit y of discovering the ' black holes' in the sy stem and substantiating the invest ment policies. This new generation of enterprises based on the concept of competitive management will be able to achieve, in an economic environment, customized products at the quality level required by the market.

\section{Simulations and discussions}

In order to succeed in de monstrating the viability of the solution to the problem of continuous identification and of adaptive and optimal running of the modelled manufacturing systems, a practical database resulted from process measurements was obviously required.

For this, m easuring and monitoring of the drilling process were made, whose results are summarized in the table 1.

Analysis of cluster is a descriptive technique used for grouping sim ilar entities from a data set o $r$ equally for entities that present evidence substantial differentiation from the group. Clustering techniques in clusters is based on algorithm $\mathrm{s}$ from the neural networks.

Clustering variables consists in group ing variables which are variables in dependence. Thu s using "best NN model", the choice of many consecutive columns and determination of the best links with the 1,2 or i variable we determine the cluster of 
variables which are in the best relationship of dependency. For example, in table 1, considering the drilling process variables that denote the $\mathrm{V}_{1}, \mathrm{~V}_{2}, \ldots$, $\mathrm{V}_{10}$ and using the "best $\mathrm{NN}$ model" facility, results the column $\mathrm{V}_{7}$ - time of drilling, as the most influential variable in determ ining the cost of operation. There are the best relatio nships with dependent columns $\mathrm{V}_{3}$ and $\mathrm{V}_{5}$.

Clustering states:

Suppose that the manufacturing system is required to execute an o peration that $\mathrm{V}_{3}=4$, an $\mathrm{d} \mathrm{V}_{5}=0.6$, where you don't find in our experiment.

Clustering states consists in identif ying groups of related records that can be points of departure for further exploration of relationships. In the process of grouping elements is necessary to e stimate the minimum distance between those elements with the function:

$$
d=\sqrt{\left(V_{3}-4\right)^{2}+\left(V_{5}-0,6\right)^{2}}
$$

The mathematical model

Mathematically can write a linear relationship:

$$
V_{7}=a \cdot V_{3}+b \cdot V_{5}
$$

Retaining the first 2 states, so for $k=2$ according to k-NN algorithm can be written:

$$
\left\{\begin{array}{l}
a \cdot 4+b \cdot 0,55=4645 \\
a \cdot 4+b \cdot 0,65=2410
\end{array}\right.
$$

which represents a system of two equations with two unknowns. Finding system solutions are obtained the values for $a$ and respectively $b$ which are replaced in the relationship (3) resulting relationship (5).

$$
V_{7}=4234,375 \cdot V_{3}-22350 \cdot V_{5}
$$

Linear model so determined will be used in modelling task-cost relati onship. This is a local model, that is only valid in the vicinity of the state in connection with which it is i nterrogated and ephemeral because after the query is dropped.

Taking the reasoning again we modelled the relationship between task and price. In $t$ his case we found that the influence variable is variable $\mathrm{V}$, using "best NN model". Similarly on determine:

$$
V_{9}=13285,68 \cdot V_{3}-80378,5 \cdot V_{5}
$$

If consider the price of a constant value that is $20 \%$ more than the average cost, we can express the profit rate for each task using relationship (1).

Returning to the our example above, the $\mathrm{V}_{3}=4$ and $\mathrm{V}_{5}=0.6$, it follows the same st eps as in modelling relationships: cost-task and task-price and obtain a mathematical relationship to $\mathrm{m}$ odel taskperformance, taking the influence variable, $\mathrm{V}_{8}$

$$
V_{8}=55,35 \cdot V_{3}-334,9 \cdot V_{5}
$$

In conclusion, if we $i$ ntroduce variations of the process parameters and a variable restriction we can get a table of solutions that will help to find common solutions through negotiation between the customer's requirements and possibilities of econom ic and technical producer.

\section{Conclusions}

Note that we prop ose to give managers a model so that they can interact with the econom ic environment (market). Practically, this happens before the actual work of manufacturing system, so we have to do with a function of antic ipation. The proposed method has $t$ he advantage of being applicable to any manufacturing system, regardless the physical nature of the process and the prod uct features. The $m$ ethod provides the extended modelling of the manufacturing system.

The level of extension is only limited by the number of the monitored state variables. The level of the modelling accuracy satisfies both the requirem ents specific to a contract negotiation and the ones specific to the operational management.

The developed algorithm allows the identification of the variables of one $m$ odel that represents the relation between the outp ut and the i nput model. This relation represents a t echnical-economic model that can control a manufacturing process without experiments and based o $\mathrm{n}$ the extraction of the knowledge from the previous experience.

The obtained mathematical model is used for the manufacturing system control, namely, to check its performances. The adaptive chara cter of the manufacturing system control is given by the change of the $\mathrm{m}$ athematical model depending on the customer requests.

The proposed method consists in determining of the causal relation between one controlled variable and the monitored variables and then predicting its value in order to realize adaptive control of the manufacturing system.

\section{References:}

[1] Christoph H. Loch, Stephen Chick and Arnd Huchzermeier, European Manufacturing Companies Compete: Industrial Competitiveness, Employment and Growth in Europe, in European Management Journal, 251265, Volume 25, Issue 4, 2007.

[2] Epureanu A., Buruiana F., Ciuntu S., Susac F., Algorithm for Economical Char acteristics Identification a Machining Sy stem, The Annals of Dunarea de Jos University of Galati, Fasc. V, ISSN 1221-4566, pp.135-139, 2007. 
[3] Francisco Restivo An Agile and Adaptiv e Holonic Architecture for Manufacturing Control, Ph. D. thesis, University of Porto, student: Paulo Leitão, supervisor, 2004.

[4] Gi-Tae Yeo, Roe M.and Dinwoodie J. Evaluating the competitiveness of container ports in Korea and China Transportation Research Part A: Policy and Practice, In Press, Corrected Proof, Available online 14 February 2008

[5] Seong Kon Lee, Gento Mogi and Jong Wook Kim - The competitiveness of Korea as a developer of hydrogen energy technology: The AHP approach Energy Policy, In Press, Corrected Proof, Available online 28 January, 2008.

[6] George F. Georgakopo ulos - Chain-splay trees, or, how to achieve and prove $\log \log N$ competitiveness by splaying, in Information Processing Letters, Volume 106, Issue 1, 31 March 2008, 37-43, 2008.

[7] Toly Chen - Evaluating the mid-term competitiveness of a product in a semiconductor fabrication factory with a systematic procedure, Computers \& Industrial Engineerin g, Volume 53, Issue 3, October 2007, 499-513, 2007.

[8] Meng-Rong Li and Yue-Loong Chang - On a particular Emden-Fowler equation with nonpositive energy $u^{\prime \prime}-u^{3}=0$ : Mathematical model of enterprise competitiveness and performance, in Applied Mathematics Letters, Volume 20, Issue 9, September 2007, 1011-1015, 2007.

[9] Christoph H. Loch, Stephen Chick and Arnd Huchzermeier - Can European Manufacturing Companies Compete?: Industrial Competitiveness, Employment and Growth in Europe, in European Management Journal, Volume 25, Issue 4, August 2007, 251265, 2007.

[10] Rodney Anthony Stewart - IT enhanced project information management in construction: Pathways to improved performance and strategic competitiveness, in Automation in Construction, Volume 16, Issue 4, July 2007, pages 511-517, 2007

[11] H'nida F., Martin P., Vernadat F. - Cost estimation in mechanical production:The Cost Entity approach applied to integrated product engineering, in International Journal of Production Economics, 103, 17-35, 2006.

[12] Lawton T. - European Industrial Policy and Competitiveness, London, Macmillan Press, 1999. [23] H'nida F., Martin P., Vernadat F. Cost estimation in mechanical production:The Cost Entity approach applied to integrated product engineering, in International Journal of Production Economics, 103, 17-35, 2006.

[13] Özbayrak M.-Activity -based cost estimation in a push/pull advanced manufacturing system, in International Journal of Production Economics 87 (1), 49-65, 2004.

[14 ] Cios K., Pedrycz W., Siniarski R.,Kurgan L.- Data Mining- A knowledge Discovery Approach, Springer, ISBN 13-978-0-387-33333-5, 2007.

[15] $* * * *$ HoloMAS $-3^{\text {rd }}$ International Conference on Industrial Applications of Holonic and Mullti-Agent Systems, september 3-5, 2007, Regensburg, Germany in conjuction with DEXA 2007 Events, 2007. 